\title{
AANTEEKENINGEN OP HAMELBERGS WERKEN
}

\author{
DOOR
}

W. R. MENKMAN.

III

Vóó r 1621 . De toestand vóór de oprichting der West-Indische Compagnie is $\mathrm{H}$. blijkbaar niet duidelijk geweest; eerst vertelt hij dat de onzen zich reeds op het einde der zestiende eeuw op den handel met West Indië toelegden, daarna dat het doel der uitrustingen naar de West voornamelijk de kaapvaart was (Ned. I, 11). Wij mogen zonder aarzeling aannemen, dat commercieele expansie beoogd werd en de kaapvaart bijkomstig was; de schepen waren echter ter verdediging bewapend en, konden zij en passant buit behalen, dan liet men de gelegenheid niet voorbijgaan.

Dat volgens notarieele acten in het Haarlemsche Rijksarchief reeds in 1567 een Enkhuizer en een Arnemuider schip zich op Cuba bevonden, was aan $\mathrm{H}$. allicht niet bekend; over Cabiliau's reis van 1597-1598 (ook naar de Caraibische Zee), spreekt hij niet, over de vijf Nederlandsche koopvaarders te Havana in 1599 evenmin, ook niet over de avonturen van Wemberich van Berghem op Cuba, heel in het begin der zeventiende eeuw ${ }^{1}$ ).

Van de zoutvaart op Bonaire en Sint Maarten vóór de oprichting der Compagnie (Ned. I, 11) is niets gebleken; welke het Westindische zout-eiland was, dat in 1599 door een Enkhuizer schipper ontdekt werd, is niet bekend, wel dat er direct veertig groote schepen heenvoeren ${ }^{2}$ ). Dat er reeds vóór 1621 Nederlandsche zoutetablissementen waren aan de kust van Venezuela staat vast

1) De Jonge, Opkomst, zie vroeger; Everhart van Reyd, Voornaemste Gheschiedenissen in de Nederlanden, 633/634, Arnhem 1626; W. I. Gids, XVIII, 214/215.

2) Van Reyd, 634, zie hooger; vergel. Bijdr. t. d. gesch. onzer kolonisatie in N. Amerika, De Gids 1848. 
en niet alleen omdat ,de Soutvaert op Ponte del Re" speciaal in het eerste octrooi der Compagnie genoemd werd ${ }^{1}$ ).

H. spreekt over de talrijke oorlogsschepen, die Spanje in zijn Amerikaansche koloniën onderhield (Ned. I, 12); het was echter juist de afwezigheid eener Spaansche maritieme macht in de Westindische wateren, welke het aan de onzen, - en al eerder aan anderen - mogelijk gemaakt heeft, in dat zeegebied door te dringen.

Inderdaad kwam daar nog bij, dat de Spaansche koloniën door haar moederland niet in voldoende mate van het noodige voorzien werden, zoodat sluikhandelaars van vreemde nationaliteit welkom waren (wat de Engelschen al lang tevoren ontdekt hadden), hoewel oogluiking ook wel door omkooping of intimidatie verkregen werd. Het doet echter vreemd aan, dat H., ter illustratie van dezen toestand, een vertoog aanhaalt van 1738 (Ned. I, D. 6), toen de kwestie van den sluikhandel in een nieuwe periode was komen te verkeeren, door de oprichting, tien jaar eerder, van de Guipuscao-compagnie. In den aanvang der achttiende eeuw verkregen de kooplieden der Baskische provincie Guipuscoa een, overigens vrij beperkt voorrecht, uitsluitend voor de vaart op de capitanía general de Caracas (Orinocomond tot Rio Hacha), een gebied dat toen reeds gedurende drie kwart eeuw speciaal voor den Curaçaoschen handel van zooveel belang geweest was $\left.{ }^{2}\right)$. De zetel van het verkeer met de nieuwe wereld was reeds in de zeventiende eeuw van Sevilla op de havenstad Cadiz overgegaan; ook voor den handel van Guipuscoa bleef Cadix de haven. De geschiedenis der achttiende eeuwsche hervormingen van het Spaansche koloniale stelsel kan hier niet verder vervolgd worden, doch zij heeft in ieder geval niet direct te maken met die onzer expansiepolitiek van vóór de oprichting der West-Indische Compagnie.

Curaçao onder Spaansch bewind. Van de Curaçaosche geschiedenis vóór 1634 zegt $\mathrm{H}$. weinig; de publicaties betreffende Ampiès (Jaarv. I, Bijlage A; Jaarv. II, Bijlage B) zijn niet door $\mathrm{H}$. onderteekend.

Aan Teenstra's mededeelingen hecht $\mathrm{H}$. weinig waarde (Ned. I, D. 213/215) en het is wellicht om deze reden dat hij geen gewag maakt van hetgeen laatstgenoemde vertelt aangaande een

1) W. I. Gids, XVII, 196.

3) Zie o.a. J. J. Dauxion Lavaysse, Voyage aux Isles de Trinidad... et dans diverses parties de Vénézuela, hoofdst. 10, Paris 1812. 
Zeeuwsch schip dat in 1523 de Caraibische Zee bezocht; T. heeft misschien iets naders willen berichten over de reis welke een $Z$ eeuw zou hebben gemaakt, op zoek naar een eiland, dat hem door Karel $\mathrm{V}$ geschonken was, zie $\left.\operatorname{Luzac}^{1}\right)$.

In de Engelsche litteratuur wordt Curaçao genoemd als in 1565 aangeloopen door John Hawkins, die er grooten veerijkdom aantrof ${ }^{2}$ ). Teenstra vertelt een handschrift te hebben ontdekt, volgens hetwelk de Graaf van Cumberland in 1593 Curaçao zou hebben bezocht, om er te ververschen; $\mathrm{H}$. levert hierop geen commentaar. George Clifford, third Earl of Cumberland, is voor zoover bekend toen niet in de Caraibische Zee geweest; wel rustte hij in 1593 een expeditie uit en de schepen kunnen inderdaad wel op Curaçao ververscht hebben (er was daar volgens Hawkins een overvloed van versch vleesch te verkrijgen), maar de Graaf zelf was op de Azoren achtergebleven, wegens ziekte. Vier of vijf jaar later zeilde Clifford met een groote vloot uit, om de Spanjaarden in West Indië afbreuk te doen; hij vertoefde toen op Dominica en pleegde een aanslag op Porto Rico, welke niet tot blijvende resultaten leidde ${ }^{3}$ ). Dan volgt het bezoek van David Middleton aan onze tegenwoordige Benedenwindsche Eilanden op de reis van 1601, waarvan indertijd Pater $\mathrm{E} \mathrm{u} \mathrm{we} \mathrm{n} \mathrm{s}$ iets mededeelde ${ }^{4}$ ); veel bijzonderheden echter kunnen aan het verhaal van den Engelschman niet ontleend worden.

De geschiedenis van Jean-Remy Perrin is volgens H. door Teenstra niet correct uit De la Porte's werk overgenomen; het eigenaardigste echter is, dat $\mathrm{T}$. den indruk gegeven heeft alsof de Bretagner zijn avonturen op Curaçao (?) in de zestiende eeuw beleefde, wat zelfs in de Encyclopedie van Ned. West-Indië overgenomen is, hoewel De la Porte en Teenstra beiden het jaartal 1602 noemen. Ook het verhaal van het bouwen van een fort op Curaçao (?) is hoogst onwaarschijnlijk.

West-Indische Compagnie. Dat de commandeur Pieter Schouten (die eigenlijk van beroep medicus geweest zou zijn) in 1624 met een eskader voor Sint Maarten zou zijn verschenen (Ned. II, 7), is een wel wat overdreven voorstelling ; zijn

$\left.{ }^{1}\right)$ E. Luzac, Holland's Rijkdom, I, Leiden 1780.

$\left.{ }^{2}\right)$ Clements, R. Markham, The Hawkins' voyages, Hakluyt Soc. 1878.

3) Dictionary of National Biogr.; Joh. de Laet, Iaerl. Verhael, bew. S. P. L. Honoré Naber (Linschoten Ver. XXXIV, 1931), 96, 98.

4) Neerlandia, Bonairenummer, 1907. 
schip de Eendracht was van hem afgeraakt en hij bevond zich nu aan boord van het andere vaartuig der expeditie, de Trouwe, een jacht van zestig lasten, dat een nieuwen boegspriet noodig had, van kalfaten wordt niet gesproken ${ }^{\mathbf{1}}$ ). Intusschen, dit bericht is inderdaad het eerste betreffende een bezoek aan de Bovenwindsche Eilanden, in de annalen der Compagnie te vinden.

Het vertoog van 11 October 1632 (Ned. I, 16, D. 7), overigens niet het eenige van dien aard, was een poging om de Hooge Regeering er van te overtuigen, dat zij verkeerd zou doen, ter wille van den vrede met Spanje en Portugal, de West-Indische Compagnie prijs te geven. Van vrede was n.l. in genoemd jaar, na den val van Maastricht, sprake en de Compagnie was toen en later voor den Koning het groote struikelblok.

Van de verlenging van het eerste octrooi in 1647 rept $H$. niet, noch van den slechten toestand waarin de Compagnie toen reeds verkeerde en van de moeilijke positie waarin ook de regeering der Republiek zich bevond, in verband met de verhouding tot Portugal en de Braziliaansche kwestie.

De liquidatie der oude Compagnie in 1674 (Ned. I, 16) was meer schijn dan werkelijkheid; een derde deel der bewindhebbers ging naar de nieuwe over en de anderen verkregen voorkeur bij vacatures ${ }^{2}$ ). De ondernemingsgeest der kooplieden, welke bij de vorming der tweede Compagnie aan den dag gelegd zou zijn, was niet zoo groot; zij beschikte als bedrijfskapitaal slechts over hetgeen door bijstorting op aandeelen en obligaties bijeen gebracht kon worden. De organisatie bleef gehandhaafd als een instrument tot het beheeren der Nederlandsche koloniën, zonder deugdelijke contrôle echter van de zijde van den staat.

Dat de kwestie van den vrijen handel (Amsterdam tegenover Zeeland) bij de beide verlengingen een rol gespeeld heeft (Ned. $I, 17)$, is juist; $H$. vermeldt echter niet hoe belangrijk deze aangelegenheid geweest is met betrekking tot Brazilië, onder het eerste octrooi, resp. bij de reorganisatie van 1647 .

Een goed overzicht van het verloop der koersen van de actiën der West-Indische Compagnie zal wel moeilijk samen te stellen zijn; dat echter een handelsonderneming als zoodanig haar belangen geschaad zou zien door ,het verminderen in waarde der aandeelen van de maatschappij" (Ned. I, 63) is een nogal aanvechtbare uitspraak; in het laatste deel der zeventiende eeuw

1) De Laet, Iaerl. Verh., 31.

2) Mr. S. van Brakel. De Hollandsche Handelscompagnieën der zeventiende eeuw, 's Hage 1908. 
evenwel was reeds de speculatiezucht over de Nederlandsche kapitalisten vaardig geworden.

De verovering van $\mathrm{Curaçao.} \mathrm{H.} \mathrm{heeft} \mathrm{geen} \mathrm{gebruik}$ kunnen maken van het rapport van Van Walbeeck (Ned. I, 22); $\mathrm{W}$ a r n s in c k heeft het teruggevonden (of een copie er van) in het archief nopens Brazilië ${ }^{1}$ ), zooals ik indertijd op dezelfde plaats een copie van het rapport van Le Grand aangetroffen heb ${ }^{2}$ ).

Van Walbeeck zal wel een kaart van het eiland opgezonden hebben, die dan wel zal zijn afgelegd bij het origineele rapport; die waarvan $H$. het bestaan vermoedde (Ned. I, D. 25) moet andere letters ter aanduiding der verschillende baaien, vestigingen enz. hebben gegeven, dan die welke De Laet gebruikte ter verduidelijking van zijn kaart ${ }^{3}$ ).

Er heeft direct een opname plaats gehad en ook Klein Curaçao (Ned. I, 37) is direct verkend ${ }^{4}$ ); aangaande het zoeken naar goud hebben de Spanjaarden ons ingelicht ${ }^{5}$ ), over de bijzondere voorzorgen ten behoeve van de van het eiland verwijderde oude bewoners rapporteerde Van Walbeeck ${ }^{6}$ ).

Dat een voorgenomen tocht naar Brazilië mede aanleiding geweest zou zijn om een aanslag op Curaçao te ondernemen (Ned. I, 21, D. 5), valt al heel moeilijk in te zien; men had het vorige jaar Sint Maarten verloren en wilde een ander steunpunt zien te bemachtigen in de Caraibische Zee, dat zal wel de reden geweest zijn voor de expeditie van 1634. Zulk een station diende zoowel voor de uit Brazilië thuisvarende schepen, als voor die welke voor operaties in de Caraibische Zee uit Nederland werden uitgezonden (Ned. I, D. 33).

Dat men niet over één nacht ijs ging, blijkt wel uit het voorschrift om, wanneer de aanslag op Curaçao mocht mislukken, de flotielje een andere bestemming te geven; behalve over de aanwijzingen van Otsen, die toch Curaçao niet zoo bijzonder goed bleek te kennen, beschikte men ook nog over die van Rijmelandt, betreffende de kust (Ned. I, 21, D. 22). Waar H. zijn gegevens aangaande dezen Rijmelandt heeft gevonden, vertelt hij niet; aan Otsen kon terecht verweten worden, dat hij de

1) De Laet, Iaerl. Ver., IV, Linschoten Ver. 1937.

2) Maandbl. Oost en West, Mei 1934.

s) Iaerl. Verh. 436/437.

•) W. I. Gids, XX, 196, 198.

b) W. I. Gids, XVII, 201

•) W. I. Gids, XX, 196. 
Compagnie met betrekking tot de Curaçaosche havengelegenheid volkomen verkeerd had ingelicht ${ }^{\mathbf{1}}$ ).

$\mathrm{K}$ a a pvaart-Zeeroof. H. vertelt nogal eens iets over dit onderwerp, maar slaagt er niet in zijn lezers een duidelijk beeld te geven van den particulieren zee-oorlog, welke in de Caraibische Zee - en elders - gedurende twee en een halve eeuw den handel heeft belemmerd, eigendom verwoest en het voortschrijden der beschaving tegengehouden. Dat enkele Engelsche en Fransche vrijbuiters min of meer waardevolle reisverhalen hebben nagelaten, weegt hiertegen niet op.

Niet alleen H., maar ook anderen hebben echter aan de kaapvaart onrecht gedaan, door haar te veel te zien als een bedrijf dat slechts weinig van zeeroof verschilde, van de wijs gebracht door de oude geschriften, waarin de partijen elkander over en weer gaarne van onwettige daden beschuldigden. Wij mogen aannemen, dat in West Indië in de zeventiende en achttiende eeuw in den regel de legitimiteit in acht genomen werd; open zeeroof was een ontaardingsverschijnsel, dat optrad toen er voor de boekaniers en flibustiers geen reden van bestaan meer was ${ }^{2}$ ). Oorlogsschepen werden hoofdzakelijk ingezet in den strijd in de Europeesche wateren; in de overzeesche gewesten der koloniale mogendheden hadden de plaatselijke gezagdragers de bevoegdheid kaperbrieven uit te reiken ten behoeve van de guerilla ter zee. De nationaliteit der gegadigden deed niet ter zake; Reyning, een Nederlander, om slechts dit eene voorbeeld te noemen, deed aan de Spanjaarden afbreuk krachtens een Engelsche commissie, maar voer direct daarna met evenveel enthousiasme onder een Spaansche commissie op de Engelschen. Zelfs was het mogelijk, dat een kaper, met een vreemden commissiebrief, tegen de koopvaardij van zijn eigen natie ageerde en de voorbeelden van een dergelijk bedrijf zijn aan te wijzen.

De kaper voer wel tevens ter koopvaardij en de koopvaardijman oefende wel tevens de kaapvaart uit, wanneer hij een commissie had; zeeroover was alleen hij die op zee gewelddaden pleegde zonder, of met een niet regelmatige of niet meer geldige commissie, waarover natuurlijk onzekerheid kon bestaan.

In oorlogstijd gaven de belligerenten over en weer kaapvaartbrieven uit en schiepen zich zoodoende een hulp-marine; daar-

1) Rapport Van Walbeeck, zie vroeger.

2) Ph. Gosse, The history of Piracy, London, 1932. 
naast echter kende men de lettres de représaille, of lettres de marque, krachtens welke de onderdanen van den eenen staat zich in vredestijd voldoening konden verschaffen voor onrecht, hun van wege een anderen staat aangedaan. Deze laatste instelling dagteekende reeds uit de middeleeuwen ${ }^{1}$ ) en nog in de vóórgeschiedenis van onzen tweeden Engelschen oorlog is van letters of marque (letters of reprisal) tegen de Hollanders sprake ${ }^{2}$ ), terwijl nog later, in 1686, een Engelschman vergoeding van zijn Koning vroeg, ,,either in money or reprisal”, voor de schade hem toegebracht door een Spaanschen overval van het eiland Tortola ${ }^{3}$ ).

Verder machtigden zoowel Engeland als Spanje particuliere scheepsbevelhebbers om zich meester te maken van vreemde vaartuigen, welke in West Indië den sluikhandel uitoefenden en derhalve de moederlandsche monopoliebepalingen ontdoken; wat dan weder aanleiding gaf tot het uitreiken van represaillebrieven door de tegenpartij. Aangezien aan beide zijden op aandeel in den buit gevaren werd, oefende men feitelijk over en weer kaapvaart uit in vredestijd; de Spaansche guarda costas hebben een groote rol gespeeld in den strijd der Engelschen voor de open deur in West Indië, vooral in de achttiende eeuw ${ }^{4}$ ).

Gevallen van open zeeroof zijn niet zoo gemakkelijk aan te wijzen; het geval van het slavenschip Sint Jan (Ned. I, D. 75, 76), ook elders beschreven ${ }^{5}$ ), was er allicht een, het deed zich echter voor kort na het in werking treden van Cromwell's navigation law, evenals de andere gewelddadigheden, in 1651, 1654, 1658 en 1659 , door H. gememoreerd (Ned. I, 43, D. 74/77).

H. noemt één voorbeeld van personen die wegens zeeroof op Curaçao veroordeeld werden (Ned. I, 140/141) en wij moeten aannemen dat het toen (1729) inderdaad om een internationaal erkend misdrijf ging.

Het octrooi der West-Indische Compagnie van 1621 sprak niet met zoo vele woorden over de kaapvaart; zij werd geacht ook voor dit bedrijf octrooi te hebben en de uitoefening er van aan anderen te kunnen toestaan, tegen aandeel in den buit ${ }^{6}$ ).

1) Richard Pares, War and Trade in the West Indies 1739/1763, Oxford 1936.

2) Japikse, Verwikkelingen, 48, 177, 312, 441, 460, 468, zie vroeger.

s) Calendar of State Papers, Am. \& W. I., 1685/1686, No. 673.

4) Pares, zie hooger.

s) Doc. ... Slave Trade..., I, sevent. cent., doc. Nos 33, 34, zie vroeger; O'Callaghan, Voy. Slavers, zie vroeger.

•) Lieuwe van Aitzema, Historie of Verhael van Saken van Staet ne Oorlogh, 3de dl., 1630/1635. 
De Roeberge's (zie Namen van Personen) moeten een consent van de Compagnie gehad hebben en van Snouck en Lettré blijkt, dat zij in 1635 van de Kamer Zeeland een commissie verkregen om (in West Indië) "te gaen cruijsen" (Ned. II, D. 13). Van de gebroeders Lampsins, de reeders van de Nieuwe Geuzen, waarvan De Ruyter er een gecommandeerd heeft, is bekend, dat zij tijdens den derden Engelschen oorlog de ,vrije nering" in de Westindische wateren lieten uitoefenen ${ }^{1}$ ). H. geeft een artikelbrief, vastgesteld door de Staten Generaal in April 1675, houdende bepalingen op de vergoedingen, waarop zij die in dienst van de West-Indische Compagnie gekwetst zouden worden, aanspraak zouden kunnen maken (Ned. II, D, 13), wat betrekking moet gehad hebben op de kaapvaart tegen de Franschen, want oorlogsvloten bracht de tweede Compagnie niet in zee en met Engeland was vrede gesloten. De directe bemoeienis der Hooge Overheid met de kaapvaart dateerde reeds van den vorigen oorlog; in Februari 1665 hadden Oost- en West-Indische Compagnie machtiging verkregen den Engelschen in en buiten Europa zooveel mogelijk afbreuk te doen en reeds in Januari van dat jaar waren kapercommissies uitgereikt door de Staten Generaal, niet meer door de admiraliteiten, onder een reglement ${ }^{2}$ ).

H. spreekt af en toe over het kaaprecht (Ned. I, 110, 171), maar zegt niet waarop dat berustte; hij noemt eenmaal het vredesverdrag van Munster (Ned. I, 171), waarop natuurlijk Spanje het recht baseerde in vredestijd aanhoudingen te doen van schepen bij den sluikhandel betrokken. Ook Engeland heeft herhaaldelijk met Spanje verdragen gesloten, welke tot vele disputen aanleiding gegeven hebben evenwel, in verband met het optreden der guarda $\operatorname{costas}^{3}$ ). Engeland, dat zelf zoo vaak het dominium maris-principe verdedigd heeft, meende dat het Amerikaansche zeegebied vrij behoorde te zijn, behoudens het recht van iedere koloniale mogendheid om haar handelsmonopolie te beschermen (recht van onderzoek in de territoriale wateren), terwijlSpanje de nieuwe wereld als haar domein bleef beschouwen, behoudens het bij verdrag aan anderen toegekende recht zich daar te bevinden.

Waarom noemt H. (Ned. II, 26) Gerard Bogaert een Hollandschen flibustier? Waarschijnlijk een te letterlijke vertaling van Du Tertre. B. was een Zeeuw en voer met een commissie van den

1) Calendar of State Papers, Am. \& W. I., 1669/1674, No. 1000.

2) Japikse, Verwikkelingen, 467, zie vroeger.

s) Pares, War and Trade, zie vroeger. 
directeur van Curaçao; flibustiers waren Fransche vrijbuiters.

In oorlogstijd traden kapers ook op tegen neutralen, wanneer die onrechtmatig verkeer onderhielden met de tegenpartij. Wat onrechtmatig was evenwel (Ned. I, 110), kon aan twijfel onderhevig zijn. Zelfs nog in den Amerikaanschen vrijheidsoorlog was het een twistpunt of de onzen krachtens het verdrag met Engeland van 1674 (Tractaat van Marine) aan Frankrijk al dan niet scheepsbehoeften konden leveren ${ }^{1}$ ). In den Spaanschen Successie-oorlog intusschen waren wij geen neutralen, doch actieve deelnemers aan het conflict, wat voor Curaçao de groote moeilijkheid medebracht, dat de vijand tevens de belangrijkste handelsrelatie was en men het verkeer gaarne wilde handhaven.

$\mathrm{Na}$ den vrede van Utrecht brak een periode van rust aan, welke duurde tot 1739 (oorlog van Engeland met Spanje, bekend als "Jenkins' ear war", wegens het gebruik dat de oorlogspartij in Engeland makte van een reeds vrij oud conflict met een guarda costa in de Caraibische Zee, waarbij captain Jenkins een oor zou zijn afgesneden). $\mathrm{H}$. vermeldt verscheidene gevallen van overlast op zee gedurende dit tijdperk (Ned. I, 135/141, 144, 145, 155, D. 139); voor zoover niet van echten zeeroof sprake was, moeten de moeilijkheden veroorzaakt zijn door de actie der Spaansche guarda costas en de tegenactie der onzen, die den sluikhandel niet wilden opgeven.

Spoedig brak de Oostenrijksche Successie-oorlog uit (1741), in 1744 werd Frankrijk betrokken in den oorlog met Engeland, in $1748 \mathrm{kwam}$ de vrede tot stand tusschen de drie partijen; de Curaçaosche handel werd in deze periode van strijd belaagd door Engelschen en Spanjaarden (Ned. I, 171/173). Evenals onder de dirctie van Du Fay (1721/1730) en die van Gales (1738/1740) tusschen de Republiek en Spanje klachten waren gerezen wegens onrechtmatige nemingen, hadden de Nederlandsche diplomaten zoodanige klachten te behandelen gehad met de Spaansche en Engelsche regeeringen tijdens de bestuursperiode van Faesch (1740/1758). Particuliere gewapende Curaçaosche schepen ageerden op de kust van Venezuela, hetzij alleen, hetzij in samenwerking met Engelschen en Franschen, in 1741, 1742 en 1743, hoewel de Republiek de facto niet in oorlog met Spanje, slechts nominaal de bondgenoote van Engeland was ${ }^{2}$ ). Het gold hier ook weder uitsluitend het belang

1) Zie o.a. J. J. Backer Dirks, De Nederlandsche Zeemacht, III, 245, 's-Hage 1890.

${ }^{2}$ ) Pares, War and Trade, zie vroeger; ook W. I. Gids, XX, 80/82. 
van den sluikhandel. Een Nederlandsche koopvaarder, op weg naar Curaçao, werd twee maal op de reis (1746 en 1747) door Engelschen genomen ${ }^{\mathbf{1}}$ ).

Bij den Zevenjarigen Oorlog (1756/1763) werd Spanje eerst in 1762 betrokken, zoodat de Spaansche klacht van 1761 (Ned. I, 178) slechts betrekking kon hebben op Curaçaosche stoutigheden als représaille tegen belemmering van den handel op de kust. Wat onze slavenschepen De Jonge Isaac en Willem Carolina in $1757 / 1759$ bij de Engelschen verdacht deed zijn, blijkt niet duidelijk ${ }^{2}$ ).

O orlogen. Na den vrede van Munster heeft een reeks van oorlogen, meer dan anderhalve eeuw lang, invloed uitgeoefend op den gang van zaken in West Indië; $\mathrm{H}$. laat ons niet altijd duidelijk zien gedurende of tengevolge van welken oorlog zekere gebeurtenissen zich voltrokken.

Het voorspel tot den tweeden Engelschen oorlog (Ned. II, $19 / 21$ ) is uitvoerig behandeld door Japikse, ook met betrekking tot onze Westindische koloniën ${ }^{3}$ ); aangaande De Ruyters optreden in de Caraibische Zee vindt men het noodige in de Engelsche litteratuur ${ }^{4}$ ) en bij de Nederlandsche biografen van den admiraal ${ }^{5}$.

H. spreekt van een Engelsch-Franschen oorlog van 1667/1668 (Ned. II, 55); het was echter in 1666 dat Lodewijk XIV, ten behoeve van de Republiek en wegens het tractaat van 1662, zich in den krijg tegen Engeland mengde.

Aangaande den tocht van Evertsen en Binckes gedurende den derden Engelschen oorlog (Ned. II, 38, 39) beschikken wij thans over een volledige beschrijving $\left.{ }^{6}\right)$. Sprekend over de expeditie van Binckes tegen Fransch West Indië in 1676, zegt H. (Jaarv. IV, 22), dat het doel der onderneming zoo goed geheim gehouden was, dat zelfs de Fransche gezant er niets van te weten kwam; gewoonlijk echter worden in oorlogstijd geen diplomatieke

1) W. I. Gids, XVI, 291, 292.

2) J. Hudig Dzn, De scheepvaart op West-Afrika en West-Indië in de achttiende eeuw, 41, Amsterdam 1926.

s) Verwikkelingen, zie vroeger.

‘) O. a. bij Harlow, Col. exped., documenten par. III, 2, 3, zie vroeger.

s) Blok, Mich. Adr. de Ruyter, zie vroeger.

-) De Zeeuwsche expeditie naar de West, zie vroeger. 
betrekkingen tusschen de oorlogvoerenden onderhouden door middel van resideerende gezantschappen. Godefroi Comte d'Estrades was Fransch gezant in Den Haag geweest, gedurende het laatste deel van den Tachtigjarigen Oorlog (1642/1648) en daarna weder ten tijde van De Witt $\left.(1662 / 1668)^{1}\right)$.

In 1682 kwam op Curaçao het bericht aan van een te verwachten oorlog met Spanje (Ned. I, 65); de Republiek echter stond destijds aan de zijde van Spanje en zij nam, met andere mogendheden, stelling tegen de Fransche aspiraties ${ }^{2}$ ).

Dat in 1689 de oorlog opnieuw uitgebroken was (Ned. II, 44), wil zeggen, dat Frankrijk op het einde van 1688 ook aan de Republiek den oorlog verklaard had (na den inval van Willem III in Engeland) en dat wij in den aanvang van het volgende jaar de oorlogsverklaring beantwoordden, waarna Engeland spoedig volgde (Augsburgsche Coalitie, Weensch Congres, Negenjarige Oorlog, vrede van Rijswijk 1697).

Met den oorlog tusschen de Republiek en Spanje van 1701/ 1702-1713 (Ned. I, 107/110, 128) wordt natuurlijk de Spaansche Successie-oorlog bedoeld, aan welken oorlog Nederland als bondgenoot van Engeland deelnam, met Oostenrijk tegen Spanje.

In 1739 gaf de Engelsche regeering letters of reprisal af tegen de Spanjaarden en een oorlog brak uit, waarin Frankrijk in 1744 betrokken werd, eindigend met den vrede van Aken in 1748, welke tevens een eind maakte aan den Oostenrijkschen Successie-oorlog, in 1741 aangevangen. Dan volgde de Zevenjarige Oorlog in 1756, eindigend met den vrede van Parijs in 1763 (Ned. I, 179). In de twee conflicten tusschen Engeland en andere mogendheden was de Republiek, krachtens tractaat, verplicht de Engelsche zijde te houden, doch metterdaad was zij neutraal en slechts uit op handelsvoordeel. Van de rol, welke Curaçao en Sint Eustatius speelden, geeft Pares bijzonderheden; in den Zevenjarigen Oorlog werd grovelijk misbruik gemaakt van de ,flags of truce", sluikhandel leverde groote voordeelen op en op Sint Eustatius verkocht men zelfs wapentuig aan de Franschen ${ }^{3}$ ). De oorlogvoerenden zelf echter maakten zich schuldig aan veel dat niet door den beugel kon.

Dat in den Amerikaanschen Vrijheidsoorlog Spanje en Nederland een tijd lang bondgenooten waren, d.w.z. beiden tegen Engeland streden (Ned. I, 180/181), is natuurlijk juist; de

1) Nouv. Biogr. gén.

2) P. J. Blok, Geschiedenis van het Nederlandsche volk, III, 247.

2) War and Trade, zie vroeger; W. I. Gids, XX, 82 en volg., 97 en volg. 
Spaansch-Engelsche oorlog brak uit in 1778, onze vierde Engelsche oorlog in 1780. Het in vrijheid stellen, door Spanje, van Curaçaosche schepelingen, die wegens smokkelhandel naar Cadix opgezonden waren, kan echter met het hooger vermelde samengaan tegen Engeland onmogelijk iets te maken gehad hebben; H. immers haalt brieven aan van 1766 en 1767 .

De vierde Engelsche oorlog wordt door $\mathrm{H}$. niet met name genoemd, doch wel maakt zijn geschiedenis melding van de maritieme actie van Curaçao uit in 1782 (Ned. I, 180). Het geval van de Machtelyna echter wordt door $\mathrm{H}$. niet beschreven ${ }^{1}$ ).

Tocht Crijnssen. H. vertelt (Jaarv. IV, 20), dat Abraham Crijnssen in 1667 optrad in Essequibo, waar de Zeeuwen zich in vorige jaren gevestigd hadden (zij waren er n.b. reeds op het eind der zestiende eeuw) ${ }^{2}$ ). Door de Franschen en Engelschen zouden zij nu volgens $\mathrm{H}$. genoodzaakt zijn geworden het land te ontruimen; de Franschen echter waren sedert 1666 onze bondgenooten en zij hebben, gesteund door de Indianen, de Engelschen in Essequibo aangevallen, die zich ten slotte moesten overgeven, toen de commandeur van Berbice, eveneens met Indiaansche bondgenooten, hen kwam bestoken, na een tocht dwars door de wildernis ${ }^{3}$ ).

Rodomontade. Bij de beschrijving van den Franschen aanslag op Curaçao van 1673 (Ned. I, 46/53, D. 92/98) heeft $\mathrm{H}$. waarschijnlijk geen gebruik gemaakt van het pamflet in de Koloniale Boekerij te Paramaribo over deze zonderlinge rodomontade ${ }^{4}$ ).

Het zal wel altijd een raadsel blijven, langs welken weg het aan Doncker gelukt is, De Baas tot den aftocht te bewegen; Dampier, die in 1681 Curaçao bezocht, hoorde daar het verhaal, dat drie- of vier en twintig jaar geleden de gouverneur het eiland aan de Franschen verkocht zou hebben, maar overleden was toen dezen het kwamen opeischen.

N.B.: Dirk Otterinck was directeur van 1670-1673, Doncker volgde hem in laatstgenoemd jaar op.

1) W. I. Gids, III, 385.

2) E. B. Zwalue, De daden der Zeeuwen gedurende den opstand tegen Spanje, 269, Amsterdam 1846.

s) Warnsinck, Ab. Crijnssen, zie vroeger.

4) W. I. Gids, VII, 279. 
Mislukte aanslag d'Estrées. Een der metgezellen van Dampier ${ }^{1}$ ) wist te vertellen dat hij eens op de Aveseilanden een ontmoeting gehad had met een Nederlandsch schip, dat de kanonnen kwam zoeken der aldaar verongelukte schepen van D'Estrees (Ned. I, 58, 59).

Aanslag Cassard. H. zal bij het beschrijven van dezen aanslag (Ned. I, 119/127, D. 114/137; Jaarv. I, Bijl. A.) wel niet beschikt hebben over het journaal in de Gentsche universiteitsbibliotheek ${ }^{2}$ ), dat een zoo belangrijke bijdrage levert tot de kennis van de gezindheid en de houding der Curaçaosche bevolking, ter gelegenheid, van de brandschatting van 1713 .

(Wordt vervolgd)

1) New voyage, zie vroeger.

2) W. I. Gids, VI, 241. 